\title{
COMPORTAMENTO ORGANIZACIONAL
}




\section{INFLUÊNCIA DO ESTILO DE LIDERANÇA NA MOTIVAÇÃO E CONFLITOS INTERPESSOAIS EM EMPRESAS FAMILIARES}

\section{LEADERSHIP STYLE INFLUENCE ON THE MOTIVATION AND CONFLICT INTER- PERSONAL IN FAMILY COMPANIES}

Juliane Ruffatto

Faculdade Meridional - IMED

Jandir Pauli

Faculdade Meridional - IMED

Augusto Rafael Ferrão

Faculdade Meridional - IMED
Data de submissão: 06 mar. 20 |6. Data de aprovação:

19 dez. 2016 . Sistema de avaliação: Double blind review. Universidade FUMEC / FACE. Prof. Dr. Henrique Cordeiro

Martins. Prof. Dr. Cid Gonçalves Filho.

\section{RESUMO}

As empresas familiares possuem grande representatividade no cenário econômico atual. Sua gestão, geralmente sob a responsabilidade de membros da família fundadora, possui uma complexidade maior, em razão da necessidade de separação entre as questões familiares e a estratégia do negócio. O objetivo deste estudo é analisar a interferência do estilo de liderança em empresas familiares, evidenciando sua influência na motivação dos colaboradores e no surgimento de conflitos interpessoais na organização. Para tanto, foi realizada uma pesquisa empírica quantitativa- descritiva, com aplicação de questionários a 156 colaboradores de 9 empresas familiares da região de Passo Fundo, Rio Grande do Sul. Os resultados obtidos por meio da análise de regressão mostram que a motivação está significativamente relacionada com a liderança. Quanto aos conflitos intergrupais, embora ele esteja presente nas organizações familiares, este não está significativamente relacionado com a atuação do líder.

\section{PALAVRAS CHAVE}

Empresas Familiares. Liderança. Estilo de Liderança. Motivação. Conflitos. 


\section{ABSTRACT}

Family businesses have great representation in the current economic scenario. Its management, usually under the responsibility of members of the founding family, has a more complex, because of the need for separation between family issues and business strategy. The aim of this study is to analyze the interference of the leadership style in family businesses, showing its influence on employee motivation and the emergence of interpersonal conflicts in the organization. Therefore, a descriptive quantitatively empirical research was conducted with questionnaires to 156 employees of 9 family businesses in the region Passo Fundo, Rio Grande do Sul. The results obtained by regression analysis show that the motivation is significantly related with leadership. As for intergroup conflict, although it is present in family organizations, this is not significantly related to the performance of the leader.

\section{KEYWORDS}

Family Companies. Leadership. Leadership Style. Motivation. Conflicts.

\section{INTRODUÇÃO}

As características da administração de uma empresa familiar vão além dos conceitos de família, sociedade e empresa. Pelo fato de a propriedade da empresa ser de uma família, é ela quem controla ou detém a maioria do capital e também são os membros da família quem ocupa a maioria dos cargos de liderança (GRZESZCZESZYN; MACHADO, 2009).

O papel do líder de uma empresa, seja ela familiar ou não, é conservar um clima harmônico e motivador dentro de seu grupo de trabalho. Cabe ao líder buscar a criação de um ambiente propício, onde os colaboradores se sintam motivados a buscar um determinado objetivo, deste modo o líder deve fornecer meios para que as pessoas se sintam engajadas à equipe e lutem por um motivo comum a todos (LEONERT, 2003).

Nesse sentido, motivação pode ser compreendida como um fenômeno con- tínuo, muito enfatizada no meio organizacional, visto que se percebeu a importância individual do funcionário para a empresa, deixando de ser apenas um executor de tarefas para ser uma peça chave para o atingimento dos objetivos. As pessoas precisam ter motivos para agir, realizar uma ação, se expressar e determinar seu comportamento. Esses motivos podem ser estimulados por fatores intrínsecos e extrínsecos (DECl; RYAN, 2008). O ambiente de trabalho (fator extrínseco) interfere na motivação tanto quanto nas expectativas do funcionário (fator intrínseco).

Nesse ambiente de trabalho também pode haver o surgimento de conflitos interpessoais, e o líder deve ser capacitado para saber gerir essa situação. $\bigcirc$ gerenciamento dos conflitos organizacionais envolve a análise dos processos que os abrangem, podendo ser entendidos como prejudiciais às organizações, pois podem instituir um clima organizacional maléfico, produto da 
criação de condições hostis e anseios de desconfiança por parte dos colaboradores (RAHIM, 2002).

Os conflitos são, na maioria dos casos, interpretados apenas de forma negativa, mas há também uma forma positiva de se entender os conflitos, com a concepção de oportunidade de correção de técnicas organizacionais. Conflitos que acontecem em empresas, nem sempre têm que ser tratados como destrutivos, pois um bom gerenciamento pode fazer com que se encontre a natureza do conflito dentro do ambiente da empresa (BACAL, 2004).

A relação liderança-conflitos-motivação ganha contornos ainda mais complexos quando o ambiente das relações humanas são as empresas familiares. Isto por dois motivos: primeiro porque em geral são os fundadores que exercem o papel de liderança e, em segundo lugar, porque a fronteira entre as questões familiares e a gestão do negócio é tênue, fazendo com que constantemente assuntos familiares influenciem na condução da empresa. Em outros termos, o contexto administrativo das empresas familiares possui características próprias, relacionadas à existência do parentesco entre seus colaboradores e também as suas relações com funcionários, não familiares.

A liderança e a tomada de decisão nestas empresas, devem ser exercidas levando em consideração estas particularidades, objetivando minimizar o surgimento de conflitos e a aumentar a produtividade e os bons resultados. Nesse sentido, o papel do líder como motivador passa a influenciar sua interação com os liderados familiares e não familiares pode influenciar tanto de forma positiva quanto negativa os resultados e conflitos (NAJJAR, 20I2).
Diante disto, o objetivo desse trabalho é descrever a influência do exercício da liderança na motivação dos funcionários e na gestão de conflitos intragrupais em empresas familiares. Para isto, foi realizado um estudo empírico de natureza quantitativodescritiva com 156 colaboradores, distribuídos em nove empresas familiares dirigidas pelos fundadores e que empregam no quadro funcional membros da família. Os dados analisados com a utilização de software estatístico e os resultados discutidos à luz da teoria.

\section{Liderança}

As organizações são compostas por pessoas, com emoções e motivos racionais distintos, sujeitos às forças do ambiente que influenciam a motivação, os relacionamentos e a liderança, entre outras dinâmicas que motivam a conduta do ser humano e da equipe onde ele se situa. $O$ gestor precisa conhecer a motivação humana e saber conduzir as pessoas, isto é, liderar.

Dentre as várias teorias sobre o tema liderança, como por exemplo a teoria dos traços (BERGAMINI, 2009), a teoria contingencial (ROBBINS, 2009), a teoria da liderança situacional (MAXIMIANO, 2008) entre outras, foi adotado neste estudo, para efeito de sustentação teórica, a proposta por Mello (2014) sobre os estilos gerenciais. Assim, segue um resumo das principais características de acordo com cada estilo gerencial.

Sobre o perfil do líder e o seu papel na empresa familiar, Najjar (20I2) infere que a dedicação deste líder na administração da empresa por ele criada muitas vezes o faz tornar-se um líder autoritário/autocrático, e as consequências da autoridade e da falta de diálogo com os subordinados levam, 
QUADRO 1 - Características dos estilos gerenciais propostas por Mello (2014)

\begin{tabular}{|l|l|}
\hline Estilo gerencial & Características \\
\hline Líder voltado para tarefa & $\begin{array}{l}\text { Estrutura seu papel e de seus subordinados na busca da rea- } \\
\text { lização de metas; enfatiza o trabalho e aspectos técnicos da } \\
\text { função, observando padrões, respeitando hierarquias, procedi- } \\
\text { mentos e métodos. }\end{array}$ \\
\hline Líder voltado para relacionamento & $\begin{array}{l}\text { Relações de trabalho caracterizadas por confiança mútua, } \\
\text { amizade. Respeita as ideias dos colaboradores e se interessa } \\
\text { por seus sentimentos. Valoriza a individualidade e enfatiza as } \\
\text { relações interpessoais como apoio, orientação e facilitação. }\end{array}$ \\
\hline Líder voltado para situação & $\begin{array}{l}\text { Aquele que tem habilidade de identificar a realidade do seu } \\
\text { ambiente de trabalho e de apontar seu estilo às exigências } \\
\text { desse ambiente. É flexível para adaptar seu comportamento de } \\
\text { acordo com as necessidades e os motivos de seus subordina- } \\
\text { dos considerando a tarefa, o relacionamento e a capacidade } \\
\text { para realização do trabalho. }\end{array}$ \\
\hline
\end{tabular}

Fonte: Adaptado de Melo, 2014.

muitas vezes, ao rompimento do processo de formação de novas lideranças entre os membros da família, e entre os demais funcionários.

Em relação ao comportamento deste líder, deve-se também considerar o que ele trata como prioridade, e o que seus familiares/funcionários entendem como prioridade. Um empreendedor fundador pode considerar que ao depositar toda a sua energia em gerir a empresa da família está adotando a postura de manter a família em primeiro lugar, pois dali vem seu sustento. Ironicamente, esta postura pode ser interpretada de modo inverso por seus familiares subordinados, pois tal dedicação pode ser considerada por estes como a empresa em primeiro lugar (DE VRIES; CARLOCK; FLORENT-TREACY, 2009).

É sabido que, na empresa familiar, a liderança principal está quase sempre nas mãos de seu fundador, que por si só apresenta as habilidades de um líder em relação à inovação, à baixa taxa de aversão aos riscos empresariais e na energia de realização. Também se sabe que muitas vezes este fundador não desenvolveu as habilida- des necessárias para coordenação de uma equipe, tais como um bom nível de comunicação com seus subordinados, o planejamento das atividades e a fixação de metas (DONATTI, 1999).

Outro fator que deve ser considerado na liderança de empresas familiares é a separação entre o ambiente profissional e o doméstico. De maneira simples: o que é da empresa deve ser discutido na empresa, e o que é de casa, deve ser discutido em casa. A adoção desta premissa, muitas vezes, evita o surgimento da maioria dos conflitos relacionados à administração das empresas familiares (GONÇALVES, 2000).

Diante do exposto, pode-se entender que a liderança, quando exercida com autoridade e individualismo, pode levar ao desânimo, à indiferença e até mesmo ao temor dos subordinados. $O$ líder, por outro caminho, deve apreciar as características individuais, analisar o desempenho da equipe de maneira justa, ser um guia das tarefas a serem desempenhadas e motivar a equipe a alcançar as metas que almeja. 


\section{Motivação}

Ao longo dos tempos, pesquisadores procuram a relação do bom funcionamento e lucratividade nas organizações com a motivação dos colaboradores. Diante de tantos processos de desigualdades, seja de ordem financeira, social ou cultural a valorização do indivíduo encontra-se fragilizada e assim para a satisfação pessoal e organizacional o comportamento humano estabelece parâmetros a serem alcançados e a motivação é condição fundamental para a aquisição dos objetivos pessoais, do trabalho e das empresas.

Alguns autores (LOCKE; LATHAN, I 990; VALLERAND; THILL, 1993) consideram a motivação humana como um processo psicológico estreitamente relacionado com o impulso ou com a tendência a realizar com persistência determinados comportamentos. No trabalho, a motivação manifesta-se pela orientação do empregado para realizar com presteza e precisão as suas tarefas e persistir na sua execução até conseguir o resultado previsto ou esperado.

Ao analisar a motivação deve-se levar em conta o indivíduo e o ambiente em que ocorre, pois, o ambiente pode interferir na motivação tanto quanto nas expectativas individuais. Tadeucci (2009) detalha que a motivação intrínseca é de caráter pessoal, e geralmente está associada a um desejo, ou seja, um motivo que move o ser humano. Os motivos podem ter diferentes origens, a saber: I) motivos emocionais, em que pesam as emoções (positivas ou negativas) sendo que estas podem ser demonstradas ou não; 2) motivos cognitivos, baseados no conhecimento, opiniões e crenças da pessoa e 3) motivos biológicos ou hereditários, que correspondem a características físicas que levam pessoas a terem motivos diferentes das outras. Por outro lado, a motivação extrínseca é baseada no pressuposto de que o comportamento vai ocorrer em uma situação determinada, o que implica em uma interação entre o sujeito e o ambiente (TADEUCCI, 2009).

Nos estudos de Erez, Kleinbeck eThierry (200I), os autores inferem que a motivação para o trabalho deve ser analisada nos níveis individual, grupal, organizacional e mesmo cultural. Com a abordagem multinível, a motivação no trabalho pode ser definida e analisada no nível do indivíduo, das equipes, dos grupos ou setores organizacionais e da organização como um todo, compreendendo assim os níveis micro, meso e macro (TAMAYO, PASCHOAL, 2003).

Deve se levar em conta que em empresas familiares há o vínculo de parentesco, - que pode influenciar o aparecimento ou a redução de motivações. $A$ motivação leva a um comportamento, que determina as decisões e escolhas finais a respeito do que está acontecendo. Spector (2006) define motivação como um estado interior que leva a pessoa a pensar uma determinada conduta e infere que a motivação está associada a uma direção (uma escolha), à intensidade (o esforço para realizar) e à persistência (o quanto insiste até realizar). Para o autor, a motivação é resultado dos desejos, necessidades e vontades.

$O$ indicador essencial de uma equipe motivada são os resultados, que podem ser avaliados em termos de lucro, participação de mercado e, de maneira relevante, satisfação interna (TAMAYO; PASCHOAL, 2003). Em organizações familiares, a identificação da empresa com a família pode ser explorada pelo líder como uma grande motivação para alcançar bons resultados. 
sucesso da empresa está relacionado com o bem-estar íntimo e profissional de seus participantes.

\section{Conflitos}

Diferentes são as definições e abordagens sobre conflitos. Essa diversidade é acarretada em grande parte pela complexidade no tratamento dos elementos que o constituem. Primeiramente, devem-se levar em conta que os conflitos estarão presentes em qualquer relação entre duas ou mais pessoas. Em uma empresa, entretanto, - assunto conflito gera a expectativa de brigas e atritos. Segundo Bornholdt (2007), expor o conflito é a forma mais madura de enfrentar o problema.

A manifestação da incompatibilidade, o desacordo ou a dissonância entre indivíduos, grupos ou organizações é considerada como um processo de conflito (RAHIM; ANTONIONI; KRUMOV et al., 2000). Este processo é visto por alguns pesquisadores das organizações (p. ex. PONDY, 1967; BLAKE; MOUTON, I 98I) como algo maléfico para as equipes de trabalho que deve ser evitado sempre que possível. Entretanto há quem defenda que o conflito é um processo inerente à dinâmica organizacional, natural das relações entre indivíduos (DIMAS; LOURENÇO; MIGUEZ, 2005; DEUTSCH, 2003). Cosier, Dalton e Taylor ( 199I) defendem que expor e discutir o conflito, permite identificar possíveis falhas e estabelecer alternativas que nortearão as tarefas e decisões do grupo. No mesmo sentido, Dimas, Lourenço e Miguez (2005), estimular a resolução de conflitos pode resultar em ganhos significativos de criatividade e inovação que estimulam o crescimento profissional do empregado e consequentemente da organização.
No contexto da empresa familiar, deve ocorrer a distinção entre conflitos interpessoais, e de interesse. Os primeiros dizem respeito a altercações entre pessoas ou grupos, já os conflitos de interesse referem-se a uma função normativa do comportamento, ao conjunto de condutas esperadas e à aplicação de valores éticos; todos eles culminam em disputas, crises e mudanças, o que pode afetar diretamente a estrutura familiar, a estrutura de propriedade, a estrutura de controle e gestão, a profissionalização e a sucessão (DESCANIO; LUNARDELLI, 2007).

Segundo Donatti (1999), a empresa e a família, quando reunidas, tendem a fracassar justamente pela sobreposição das relações familiares com as empresariais. Para que isto não ocorra, deve-se ter em mente que não é a família que atrapalha a empresa, porém a ignorância e, aqui também deve-se levar em conta até mesmo o desinteresse, dos problemas do relacionamento empresa/família, ou seja, a falta de um código de relacionamento que imponha limites no que é de âmbito privado e familiar, e no que é de âmbito administrativo e organizacional, buscando diminuir o surgimento de conflitos.

Aqui se pode fazer um importante aparte: considera-se até então que o conflito entre gerações e os conflitos entre os familiares são os principais conflitos a serem considerados quando se fala em empresa familiar. Porém, segundo Queiroz (2008), este conflito não é mais exclusividade das empresas familiares, e pode ocorrer em qualquer organização.

As principais forças em conflito que têm contexto estabelecido exclusivamente em empresas familiares são os objetivos da empresa e os objetivos da família, ou seja, 
por um lado, a empresa tem como objetivo o lucro, devendo atingir este fim; por outro lado, entretanto, a busca pelo lucro pode não ser vista com bons olhos na família, instituição onde teoricamente prevalece o chamado bem comum (TILLMANN; GRZYBOVSKI, 2005). Deste modo, a empresa familiar por si só já tem caráter contraditório, ora favorecendo a lógica econômica, ora priorizando os interesses familiares.

De acordo com De Sá Freire, Soares, Nakayama e Spanhol (20l0), para alcançar os objetivos das mudanças será necessário um novo olhar sobre a integração intraorganizacional, para eliminar características de empresa familiar como a falta de diálogo que dificulta a solução de conflitos e as decisões impositivas que prejudicam a transposição das ideias à prática.

Baseado no exposto, acredita-se que os diferentes estilos de liderança tenham influência significativa na motivação dos colaboradores, bem como nos conflitos interpessoais em empresas familiares. Diante disso, as seguintes hipóteses de estudo foram levantadas:

Hipótese I a: $O$ estilo de liderança afeta significativamente a motivação dos colaboradores de empresas familiares;

Hipótese Ib: $O$ estilo gerencial do líder por tarefa possui uma relação positiva e significativa com a motivação dos colaboradores e é o estilo que mais influência nos conflitos nas empresas familiares.

Hipótese 2a: $O$ estilo de liderança possui uma relação negativa e significativa com os conflitos nas empresas familiares.

Hipótese 2b: $O$ estilo gerencial do líder por relacionamento possui uma relação negativa e significativa com os conflitos e é o estilo que mais influência nos conflitos nas empresas familiares.

\section{MÉTODO}

Tendo em vista a consecução dos objetivos anunciados anteriormente, foi realizada uma pesquisa de natureza descritiva, abordagem quantitativa, e de corte transversal. Para tanto, compuseram a amostra I 56 funcionários (membros ou não-membros das famílias proprietárias) de nove empresas familiares da região norte do estado do Rio Grande do Sul. Essas empresas de pequeno e médio porte de diferentes setores, com no máximo 20 funcionários, e, onde o líder é o proprietário. A técnica de amostragem utilizada foi a não probabilística, feita por conveniência e de forma não-aleatória, ou seja, foi definida conforme disponibilidade do respondente a partir do convite do pesquisador.

Os 156 funcionários responderam um questionário estruturado com questões fechadas e voltadas para as variáveis estudadas (motivação, conflitos e liderança). O "estilo de liderança" como variável independente e "motivação" e "conflitos" como variáveis dependentes. Essas variáveis foram mensuradas através de uma escala de sete pontos de variação do tipo Likert, com respostas que variam de "não concordo" até "concordo plenamente". Para verificar essas variáveis, foram aplicados 03 inventários: I) Escala de Avaliação do Estilo Gerencial (EAEG) (MELO, 20l4); 2) Inventário da Motivação e do Significado do Trabalho (IMST) (SIQUEIRA, 2008); 3) Escala de Conflitos Intragrupais (ECl) (MARTINS;ABAD; PEIRÓ, 20I4).

A coleta de dados foi realizada em horário estabelecido pela direção das empresas pesquisadas, sendo que estas foram selecionadas conforme a conveniência para o entrevistador. A aplicação do questionário foi realizada nas dependências 
das empresas participantes, após a autorização da direção no período entre março e abril de 2015.

Para o tratamento dos dados, utilizou-se o software Statistical Pack age for the Social Sciences (SPSS), versão 20.0. Para a análise das variáveis, foram realizadas estatísticas descritivas a cada grupo de variáveis. Também foi realizado o teste de confiabilidade (Alfa de Cronbach) das escalas adotadas. $\mathrm{Na}$ análise de regressão, o tamanho do efeito foi obtido por meio dos coeficientes de regressão padronizados, calculados para cada modelo (HAIR, 20I0).

\section{RESULTADOS \\ Perfil da amostra}

Foram aplicados I 56 questionários para a realização desta pesquisa quantitativa, sendo que a maioria $(51,9 \%)$ dos respondentes pertencem ao sexo masculino, apresentam idade média de 24 anos, trabalham na empresa há menos de 5 anos (42,9\%), e quanto à renda mensal do entrevistado, é possível verificar que a maioria dos indivíduos recebem até $\mathrm{R} \$ 2.500,00$ mensais.

\section{Estatísticas Descritivas}

O primeiro construto observado - motivação, a estatística descritiva apresentou bons índices da variável nas empresas familiares pesquisadas (média de $5,12 \mathrm{I}$ ), e as dimensões que mais contribuem para isto são condições materiais de trabalho $(5,320)$ indicando quanto no trabalho se pode contar com equipamentos adequados, segurança, higiene, assistência e amparo social; responsabilidade $(5,294)$ sugerindo que no trabalho se assume responsabilidades, sente-se produtivo e, por isso, uma pessoa digna e respeitadora; e auto expressão $(5,100)$ apontando que o trabalho repre- senta concretamente possibilidades de opinar, influenciando nas decisões, de expressar a criatividade, de merecer confiança e reconhecimento e crescer pessoalmente (BORGES;ALVES FILHO, 2003).

Para conflitos intergrupais a estatística descritiva apresentou uma média de 4,20I, valor levemente acima da média que caracteriza o estabelecimento de um ambiente conflitivo, isto é, segundo Martins, Abad e Pieró (2014) médias acima de quatro permitem concluir que o ambiente pesquisado pode ser qualificado como conflitivo. Neste sentido, observou-se que os conflitos por relacionamento são os que mais contribuem $(4,8 \mathrm{II})$, indicando desacordos nas relações interpessoais baseadas em animosidade entre os componentes do grupo, incluindo incompatibilidade de personalidade.

Os resultados não permitem concluir sobre um estilo gerencial típico ou preponderante, mas há uma leve tendência ao estilo de líder por tarefa, que estrutura seu papel e de seus subordinados na busca da realização de metas com ênfase na rotina de trabalho.

Para os três constructos deste estudo (motivação, conflitos e liderança) os valores dos coeficientes de alfa observados demonstraram-se satisfatórios. $\mathrm{Na}$ avaliação da confiabilidade para o Inventário da Motivação e do Significado do Trabalho (IMST), o escore total foi de, 0,936 , ficando acima do índice de validação da escala (BORGES; ALVES-FILHO; TAMAYO, 2008), bem como para suas dimensões. $A$ análise da totalidade dos elementos da escala para "conflitos" apresentou o índice de confiabilidade de 0,856, superior ao escore encontrado no teste de validação do instrumento (MARTINS; ABAD; PEIRÓ, 2008). No escore levantado a partir das dimen- 
TABELA 1 - Estatística descritiva das escalas observadas

\begin{tabular}{l|l|l}
\hline Variável & Médias & Alpha de Cronbach \\
\hline Motivação & $\mathbf{5 , 1 2 1 5}, 936$ \\
\hline Auto expressão & 5,1004 & 0,860 \\
\hline Desgaste e Desumanização & 4,8782 & 0,780 \\
\hline Responsabilidade & 5,2949 & 0,924 \\
\hline Recompensa e independência econômica & 4,9252 & 0,810 \\
\hline Condições materiais de trabalho & 5,3205 & 0,898 \\
\hline Conflitos Intragrupais & $\mathbf{4 , 2 0 1}$ & $\mathbf{0 , 8 5 6}$ \\
\hline Relacionamento & 4,8113 & 0,754 \\
\hline Tarefa & 3,5913 & 0,815 \\
\hline Estilo gerencial & $\mathbf{4 , 9 9 7 3}$ & $\mathbf{0 , 9 4 1}$ \\
\hline Líder por Relacionamento & 4,8113 & 0,941 \\
\hline Líder por Tarefa & 5,2340 & 0,801 \\
\hline Líder Situacional & 5,0609 & 0,817 \\
\hline
\end{tabular}

Fonte: Dados da pesquisa (2015).

sões da escala foi constatado $\alpha=0,754$ para conflito de relacionamento e de 0,815 para conflito de tarefa. Para a Escala de Avaliação do Estilo Gerencial (MELO, 20I4) o alfa foi de 0,941 , permanecendo acima do índice de validação da escala. O que aconteceu também com as dimensões da escala: relacionamento $(0,94 \mathrm{I})$, tarefa $(0,80 \mathrm{I})$ e situacional $(0,817)$.

A partir dos resultados apresentados na Tabela I pode-se inferir que todas as três escalas utilizadas para medida de motivação (IMST), conflitos (ECl) e estilo gerencial (EAEG) bem como suas dimensões tiveram confiabilidade atestada. $O$ valor mínimo aceitável para o alfa é 0,70 , valores abaixo disso configuram uma escala de consistência interna baixa. Porém, o valor máximo esperado é 0,90; acima deste valor, pode-se considerar que há redundância ou duplicação, ou seja, vários itens estão medindo exatamente o mesmo elemento de um constructo devendo estes ser eliminados. Usualmente, são preferidos valores de alfa entre 0,80 e 0,90 (STREINER, 2003).

\section{Análise de regressão}

Nas Tabelas a seguir, estão expostos os resultados das análises de regressão, denotando o poder explicativo do estilo gerencial para a motivação e conflitos. Os resultados observados permitem analisar as hipóteses enunciadas nesta pesquisa, verificando se a relação é ou não significante. Para ser significante, a significância ( $P$ ) deve ser menor que 0,05.

A primeira hipótese $(\mathrm{HIa})$ testou se $\mathrm{o}$ estilo de liderança afeta a motivação dos colaboradores de empresas familiares. Os resultados mostram um efeito positivo e significativo da variável independente (estilo gerencial) sobre a motivação (variável dependente).

Na Tabela I, expõe-se o resultado da regressão linear entre o estilo gerencial e a motivação. Os resultados evidenciam que o estilo gerencial possui um efeito positivo e significativo sobre a motivação dos 
TABELA 2 - Regressão - Motivação

\begin{tabular}{l|c|c|c|c}
\hline Variável Independente & Beta & $\mathbf{t}$ & Significância & $\mathbf{R}^{\mathbf{2}}$ \\
\hline Estilo gerencial & 0,692 & 11,89 & 0,000 & 0,479 \\
\hline a. Variável Dependente: Motivação & & & & \\
\hline
\end{tabular}

Fonte: Dados da Pesquisa (2015).

funcionários $(\beta=0,69 ; p<0,00$ I). A percepção do indivíduo de como seu chefe age na organização explica $48 \%\left(R^{2}=0,479\right) d a$ sua motivação, ou seja, quanto maior é a percepção do comportamento do gestor pelo subordinado, maior é a sua motivação.

Os resultados observados na Tabela 2 , a seguir, permitem analisar a segunda hipótese (HIb) enunciada nesta pesquisa. Esta hipótese buscou testar se o líder por tarefa é o estilo gerencial que mais influência na motivação dos subordinados em empresas familiares.

Os resultados mostraram um efeito positivo e significativo para o estilo líder por relacionamento $(\beta=0,27 ; p<0,0$ I $)$ e com nível maior de significância para o estilo líder por tarefa $(\beta=0,50 ; p<0,00 \mathrm{I})$, não apresentando valores significativos para o estilo de líder situacional $(\beta=0,04 ; p=0,67)$.

Como se pode verificar, comparado aos outros estilos, o líder por tarefa que é aquele voltado para realização de me- tas, os aspectos técnicos da função, aos métodos e procedimentos é o estilo que mais interfere na motivação dos subordinados $(\beta=0,50 ; p<0,00 \mathrm{I})$. Assim, pode-se confirmar a segunda hipótese $(\mathrm{HI}$ ) $)$, cuja premissa baseou-se na influência do estilo gerencial - líder por tarefa na motivação dos subordinados em empresas familiares comparado aos outros estilos.

Além dos testes de influência do estilo gerencial na motivação, foram feitos os testes de hipótese para verificar as relações entre o estilo gerencial e os conflitos intragrupais $(\mathrm{H} 2 \mathrm{a}$ e $\mathrm{H} 2 \mathrm{~b})$. Os resultados indicam que $o$ estilo gerencial tem efeito negativo e significativo sobre os conflitos, confirmando a hipótese H2a. Evidenciando que a percepção do estilo gerencial por parte dos subordinados, de como o líder age na organização, interfere na intensidade de conflito percebido nas organizações familiares.

TABELA 3 - Regressão - Motivação

\begin{tabular}{l|c|c|c}
\hline Variáveis Independentes & Beta & t & Significância \\
\hline Líder por Relacionamento & 0,278 & 2,527 & 0,013 \\
\hline Líder por Tarefa & 0,500 & 7,318 & 0,000 \\
\hline Líder Situacional & 0,044 & 0,426 & 0,670 \\
\hline a. Variável Dependente: Motivação & & & \\
\hline
\end{tabular}

Fonte: Dados da Pesquisa (2015).

TABELA 4 - Regressão - Conflitos

\begin{tabular}{l|c|c|c|c}
\hline Variável Independente & Beta & $\mathbf{t}$ & Significância & $\mathbf{R}^{2}$ \\
\hline Estilo gerencial & $-0,270$ & $-3,48$ & 0,001 & 0,07 \\
\hline a. Variável Dependente: Conflitos & & & & \\
\hline
\end{tabular}

Fonte: Dados da Pesquisa (2015). 
Como se pode verificar, o estilo gerencial percebido pelos subordinados tem efeito negativo e significativo sobre os conflitos $(\beta=-0,27 ; p<0,00 \mathrm{I})$, concluindo que a relação do estilo gerencial com os conflitos é negativa.Além disso, convém destacar que o estilo gerencial percebido explica $7 \%$ $\left(R^{2}=0,07\right)$ dos conflitos, ou seja, cerca de $7 \%$ da variância dos conflitos é explicada pelo perfil do líder.

Por fim, foi realizada a análise de regressão da quarta hipótese $(\mathrm{H} 2 \mathrm{~b})$ para verificar se o estilo gerencial do líder por relacionamento é o estilo que mais influência nos conflitos nas empresas familiares.

Como se pode verificar através dos dados acima obtidos, o estilo de liderança líder por relacionamento possui um efeito significativo e negativo nos conflitos $(\beta=-0,49$; $p<0,00 \mathrm{I})$, bem como o estilo líder por tarefa $(\beta=-0,21 ; p<0,05)$. Já o estilo líder situacional possui um efeito significativo e positivo com os conflitos nas organizações $(\beta=0,43$; $p<0,0$ I), sugerindo que que esse estilo de líder interfere positivamente na intensidade de conflito percebido pelos subordinados, ou seja, enquanto o estilo de líder por relacionamento e o líder por tarefa reduzem a intensidade de conflito, no estilo de liderança situacional esta relação é inversa.

$\mathrm{Na}$ relação com os conflitos, o líder por relacionamento é o perfil que exerce maior influência nos conflitos, visto que este perfil aborda questões acerca da co- municação, sentimentos dos subordinados, acessibilidade ao chefe, amabilidade do líder, confiança, ou seja, aspectos bastante relacionados às relações entre o gestor e seus subordinados.

\section{DISCUSSÃO DOS RESULTADOS}

Ao analisar a interferência do estilo de liderança na motivação dos colaboradores, obteve-se um resultado que permite interpretar que $48 \%$ dos respondentes se dizem influenciados pelo estilo de liderança na sua motivação, evidenciando o estudo de Torres (2005) sobre o papel do líder na motivação dos subordinados em contexto de empresa familiar. Para o autor, liderança é um processo pelo qual uma pessoa influencia outras da equipe em busca da efetivação dos objetivos organizacionais, pode-se entender assim que o líder deve mostrar-se como principal motivador da equipe. Nota-se assim que o líder pode interferir diretamente na motivação dos colaboradores, tanto positivamente, quanto negativamente.

Com base na mesma análise, observa-se que o estilo de liderança por tarefa é o que mais interfere na motivação dos colaboradores. Este perfil gerencial conduz seus subordinados de forma a alcançarem resultados quantitativos, de forma rápida e eficaz. Conforme ressalta McGregor (1980), é comum verificar o estilo do líder voltado para tarefa em organizações jovens, ainda lutando para se firmar, como é o caso da

TABELA 5 - Regressão - Conflitos

\begin{tabular}{|c|c|c|c|}
\hline Variáveis Independentes & Beta & $\mathbf{t}$ & Significância \\
\hline Líder por Relacionamento & $-0,497$ & $-3,340$ & 0,001 \\
\hline Líder por Tarefa & $-0,216$ & $-2,334$ & 0,021 \\
\hline Líder Situacional & 0,430 & 3,107 & 0,002 \\
\hline a. Variável Dependente: Conflitos & & & \\
\hline
\end{tabular}

Fonte: Dados da Pesquisa (2015). 
maioria das empresas que compuseram a amostra deste estudo.

Mesmo que o estilo gerencial por tarefa tenha se sobressaído aos demais estilos, as médias das respostas ficaram bastante próximas, sugerindo uma liderança considerada “meio termo", nem está totalmente interligada as tarefas em termos de totalidade gerenciais, nem está totalmente acarretada de situações. Significando que o líder está, no geral, causando uma boa imagem, relacionando-se com as tarefas a serem realizadas, apoiando-se em seus relacionamentos grupais e gerenciando as situações que surgem no dia-a-dia da organização.

Foi constatado que nessa orientação mais voltada para as tarefas, os objetivos organizacionais devem estar aliados às metas individuais, caminhando sempre lado a lado, para uma maior satisfação do liderado, o que também pode proporcionar melhores resultados organizacionais para a empresa.

Quanto aos conflitos, eles estão presentes nas empresas abordadas, o que nos permite concluir que tratamos de ambientes conflitivos, indicando desacordos nas relações interpessoais baseadas em animosidade entre os componentes do grupo, incluindo incompatibilidade de personalidade. Porém, a relação do estilo gerencial com os conflitos apresentou baixo poder explicativo, apenas 7\% dos conflitos são explicados pela influência do estilo gerencial. Esse resultado diverge dos achados de Donatti (1999), pois segundo ele, as empresas familiares têm maior tendência à conflitos, visto que pode haver problemas do relacionamento empresa/família envolvendo seus líderes. Este resultado sugere que outros fatores não levantados neste estudo devem determinar os conflitos intragrupais nas empresas familiares pesquisadas.
Outro resultado bastante importante foi a relação positiva entre o líder situacional com os conflitos, sugerindo a inabilidade deste perfil de tratar com conflitos. Por mais que as características deste líder se estruturem na habilidade de identificar a realidade do seu ambiente de trabalho e de apontar seu estilo às exigências desse ambiente (MELO, 20I4), este perfil é percebido como inapto para gestão de conflitos pelos seus subordinados.

Por fim, enquanto que o líder por tarefa está focado no "fazer", pode expressar inabilidade na gestão de conflitos, ele é visto como um perfil motivador e o perfil com melhores habilidades para gestão de conflitos é o líder por relacionamento pela sua característica comunicativa, sentimentos dos subordinados, acessibilidade ao chefe, amabilidade do líder, confiança, ou seja, aspectos bastante relacionados às relações entre o gestor e seus subordinados.

\section{CONSIDERAÇÕES FINAIS}

Este estudo partiu da concepção de que os objetivos organizacionais só serão alcançados na medida em que os colaboradores que realizam seus distintos trabalhos se sintam motivados, ou seja, quando os funcionários alcançam seus objetivos pessoais dentro da organização. Nesse contexto, o papel desempenhado pelo líder adquire uma importância estratégica, pois é ele quem vai articular as ações e estratégias entre os objetivos da empresa e dos colaboradores para que ambas as partes se sintam satisfeitas.

Além da interferência do líder na motivação, este estudo também traz achados importantes quanto aos conflitos intragrupais que podem influenciar tanto de forma positiva quanto negativa $\circ$ ambiente 
da empresa familiar. De forma positiva, faz com que os colaboradores se estimulem para incrementar novos conhecimentos e novas habilidades. Por outro lado, sob a ótica negativa, os conflitos podem fragilizar o ambiente de trabalho. Os dados evidenciam que o estilo de liderança orientado para o relacionamento interfere nos conflitos intragrupais, especialmente os de ordem afetiva.

Se as empresas se recusarem a resolver os conflitos e tentar sufocá-los, correm o risco de estagnarem ou até de entrarem em falência. $O$ líder precisa ter competências, habilidades e atitudes para gerir os conflitos. Caso contrário, se for excessivo ou ignorado pode provocar a diminuição da satisfação, o absenteísmo e a diminuição da produtividade.

Além disto, um dos principais resultados do estudo é mostrar a relação entre liderança e motivação. Diferente do chefe, o líder é um profissional com perfil diferenciado que cumpre, além das atribuições do seu cargo, o papel de inspirar pessoas, alavancar resultados, resolver conflitos e trabalhar para motivação de sua equipe. Suas características peculiares o tornam referência para seus subordinados. Nas or- ganizações familiares, os fundadores nem sempre aceitam que esse papel seja desempenhado por uma pessoa fora da família, mesmo que não tenham habilidade para tal função. Assim, a humanização da liderança e a harmonia das relações entre o líder e seus subordinados pode contribuir para criação de um sentimento de segurança e motivação, gerando cada vez mais produtividade e isto, no médio e longo prazo, refletirá na longevidade da empresa familiar.

Neste sentido, os achados deste estudo podem incentivar, em organizações familiares, a avaliação do estilo de liderança e como este interfere na motivação dos colaboradores e nos conflitos interpessoais. Os resultados da pesquisa não esgotam o assunto, pelo contrário, abrem a necessidade de realização de novos estudos para avaliar com mais profundidade as razões do surgimento dos conflitos em empresas familiares, as estratégias dos líderes para sua gestão, bem como os elementos motivacionais que explicam o comprometimento dos colaboradores nestas organizações. Sugere-se também a análise em grupos separados (membros da família e não familiares) para verificar as diferentes percepções entre os grupos. 
BACAL, R. Organizational Conflict The good, the bad, and the ugly. In: The Journal for Quality \& Participation. EUA. 2004.

BERGAMINI, C. W. Liderança: administração do sentido. 2. ed. São Paulo. Atlas, 2009

BLAKE, R. R.; MOUTON, J. S. Management by $\mathrm{Grid} \otimes$ principles or situationalism: Which? Group \& Organization Management, v. 6, n. 4, p. 439-455, I98I.

BORGES, L. O.;ALVES FILHO,A.A estrutura fatorial do Inventário do Significado e Motivação do TrabaIho, IMST. Avaliação Psicológica, v. 2, n. 2, p. 123- |45, 2003.

BORGES, L. O. ALVES-FILHO, A., TAMAYO, Á. Motivação e significado do trabalho. In: SIQUEIRA, M. M. $M$. et al. Medidas do comportamento organizacional: ferramentas de diagnóstico e de gestão. São Paulo:Artmed Editora S.A., p. 215-248, 2008.

BORNHOLDT, W. Governança na empresa familiar: implementação e prática. Porto Alegre: Bookmann, 2007.

COSIER, R. A.; DALTON, D. R.; TAYLOR III, L. A. Positive effects of cognitive conflict and employee voice. Employee Responsibilities and Rights Journal, v. 4, n. I, p. 7-II, I99I.

DE SÁ FREIRE, P.; SOARES, A. NAKAYAMA, M. SPANHOL, F. J. Processo de sucessão em empresa familiar: gestão do conhecimento contornando resistências às mudanças organizacionais. JISTEM-Journal of Information Systems and Technology Management, v. 7, n. 3, p. 713-736, 2010.

DE VRIES, M. F. K.; CARLOCK, R. S.; FLORENT-TREACY, E. A Empresa Familiar no Divã: uma perspectiva psicológica. Bookman Editora, 2009.

$D E C I$, E.; RYAN, R. M. Self-determination theory: A macrotheory of human motivation, development, and health. Canadian Psychology/Psychologie canadienne, $v$. 49, n. 3, p. 182, 2008.

DESCANIO, Denise; LUNARDELLI, Maria Cristina. Saúde e qualidade de vida na empresa familiar. Revista Psicologia Organizações e Trabalho, v. 7, n. I, p. 159-177, 2007.

DEUTSCH, M. Cooperation and Conflict: a personal perspective on the history of the social psychology study of conflict resolution. In M. A. West, D. Tjosvold \& K. G. Smith (Eds.), International Handbook of Organizational Teamwork and Cooperative Working, p. 8-43, 2003.

DIMAS, I. D.; LOURENÇO, P. R.; MIGUEZ, J. Conflitos e Desenvolvimento nos Grupos e Equipas de Trabalho-uma abordagem integrada. Psychologica, v. 38, p. $103-$ II 9, 2005.

DONATTI, L. Empresa Familiar: a empresa familiar em um âmbito global. Caderno de Pesquisas em Administração, v. I, n. I0, 1999.

GONÇALVES, J. S. R. C. As empresas familiares no Brasil. Revista de Administração de empresas, v. 40, n. I, p. 7-12, 2000.

EREZ, M.; KLEINBECK, U.; THIERRY, $\mathrm{H}$. Work motivation in the context of a globalizing economy. London: Lawrence Erlbaum, 2001.

GRZESZCZESZYN, G.; MACHADO, H. V. Empresas familiares do setor moveleiro e desenvolvimento local em Guarapuava/PR. O\&S Salvador, v.16 - n.5I, p. 749-769 -
Outubro/Dezembro, 2009.

HAIR, J. R. et al. Multivariate Data Analyses. 7. ed. New Jersey: Pearson, 2010.

LOCKE, E. A.; LATHAM, G. P. Work motivation and satisfaction: Light at the end of the tunnel. Psychological science, v. I, n. 4, p. 240246, 1990.

LOENERT, M. A. Motivação e liderança: um trabalho em equipe nas organizações. Revista Eletrônica de Ciência Administrativa (RECADM), v. I, n. 2, 2003.

MARTINS, M. C. F, ABAD, M. Z. PEIRÓ, J. M. Conflitos no ambiente organizacional. In M. M. M. Siqueira (org.). Novas Medidas do Comportamento Organizacional. Porto Alegre, Artmed, p. |32-|46, $20 \mid 4$.

MAXIMIANO,A. C.A. Teoria Geral da administração: da revolução urbana à revolução digital. 6. ed. São Paulo:Atlas, 2008.

MCGREGOR, Douglas. 0 lado humano da empresa. São Paulo: Martins Fontes, 1980.

MELO, E. A. M. Liderança gerencial. In M. M. M. Siqueira (org.). Novas Medidas do Comportamento Organizacional. Porto Alegre: Artmed, p. |32-|46, 2014.

NAJJAR, E. Autocracia na liderança da empresa familiar. Disponível em: http://exame.abril.com. br/rede-de-blogs/blog-do-management/2012/10/23/autocracia-na -lideranca-da-empresa-familiar/. Acesso em: 05/09/2015.

PONDY, Louis R. Organizational conflict: Concepts and models. Administrative science quarterly, p. 296-320, 1967.

QUEIROZ,V.S.The good, the bad and the ugly: estudo sobre pequenas $\mathrm{e}$ medias empresas familiares brasileiras a partir da teoria da ação 
de Pierre Bordieu. Cad. EBAPE - BR, v. 6, n. I, 2008.

RAHIM,M.A.;ANTONIONI, D.; KRUMOV, K.; ILIEVA, S. Power, conflict, and effectiveness: A cross-cultural study in the United States and Bulgaria. European Psychologist, v. 5, n. I, p. 28, 2000.

RAHIM, M.A. Toward a theory of Managing Organizational Conflict. In The International Journal of Conflict Management, 2002.

ROBBINS, S. P. Fundamentos do comportamento organizacional. São Paulo: Pearson Prentice Hall, 2009.
SPECTOR, P. E. Psicologia nas organizações. São Paulo: Saraiva, 2006.

STREINER, D. L. Being inconsistent about consistency: when coefficient alpha does and doesn't matter. Journal of Personality Assessment. v. 80, p. 217-222. 2003.

TADEUCCI, M. S. R. Motivação e liderança. Curitiba: IESDE Brasil S.A., 2009.

TAMAYO,A.; PASCHOAL,T.A relação da motivação para o trabalho com as metas do trabalhador. Revista de Administração Contemporânea, v. 7, n. 4, p. 33-54, 2003.
TILLMANN, C.; GRZYBOVSKI, D. Sucessão de dirigentes na empresa familiar: estratégias observadas na família empresária. Organizações \& Sociedade, v. 12, n. 32, p. 45-6I, 2005.

TORRES, C. V. Liderança e valores culturais: dois conceitos inter -relacionados? Em: TAMAYO, A.; PORTO, J. B. Valores e comportamentos nas organizações. $p$. 187-200, 2005.

THILL, E.; VALLERAND, R. Introduction à la psychologie de la motivation. [Laval, Québec]: Éditions Études vivantes, 1993. 